\title{
Skin and Toe Resistance Mobilisation of Pile During Laboratory Static Load Test
}

https://doi.org/10.2478/sgem-2018-0001

received September 12, 2017; accepted February 23, 2018.

\begin{abstract}
This article shows the mathematical method to determine the lateral stress on the shaft and toe resistance of pile using the new approach. The method was originally invented by Meyer and Kowalow for the static load test. The approximation curve was used for the estimation of both settlement curve and toe resistance curve of the pile. The load applied at the head of the pile is balanced by the sum of two components: the resistance under the toe of the pile and the skin friction. Therefore, the settlement curve is compilation of two factors: the skin friction curve and the resistance under toe curve. The analysis was based on the verification of the methods using laboratory experiments, that is, static load tests. The results of the research allowed to determine the relationship between parameters of the Meyer-Kowalow curve. On the basis of the relationships, it was possible to determine the skin friction and the toe resistance of the pile. Mathematical analysis of curve parameters allowed to determine the influence of the toe resistance on the settlement.
\end{abstract}

Keywords: Pile; static load test; skin friction; toe resistance.

\section{Introduction}

Static load test is a method that most accurately describes the operating conditions of the pile. During the test, settlement of pile head corresponding to the degree of load was measured. It gives a set of points $\left\{N_{i}, s_{i}\right\}$ that can be plotted on a graph as the settlement curve. The force applied at the head of the pile is transferred to the ground by the sum of two components: the resistance under the toe of the pile and the skin friction. Therefore, the settlement curve is compilation of two curves: the

\footnotetext{
*Corresponding authors: Zygmunt Meyer, Krzysztof Żarkiewicz, Department of Geotechnical Engineering, West Pomeranian University of Technology, Szczecin, Al. Piastów 50, 71-310 Szczecin Poland, E-mail:meyer@zut.edu.pl, kzarkiewicz@zut.edu.pl
}

skin friction curve and the resistance under toe curve. Settlement curve depends on the process of mobilisation of skin friction and toe resistance because of settlement progress. Likewise, the settlement curve contains information about the process of load distribution in soil. For further analysis, the results of pile load tests need to be described by mathematical equation. There are a number of methods for interpreting static load tests [1], [2]. One of them is the approximating curve proposed by Meyer and Kowalow, which allows us to describe the settlement curve using three parameters: $C, N g r$ and $k$. The parameters of the Meyer-Kowalow methods establish the relationship between the geometry of the pile, the parameters of soil and the way of load distribution. Further on, the method is denote as M-K. More about this method is presented by Meyer [4] Szmechel [9] and Żarkiewicz [6].

The formation of the skin friction and the resistance under the toe of the pile is very important, because this information is essential for pile design. It turns out that the rate of skin friction mobilisation and resistance under the toe of the pile are completely different. Moreover, the maximum values of skin friction and toe resistance are mobilised at different settlement value. The resistance distribution in an ultimate limit state, which is the basis of the design method, may be completely different from the resistance distribution in the real conditions of pile-soil interaction. Conclusions similar to that were also received by Krasiński, Gwizdała [3], Salgado and Prezzi [7].

Axially loaded pile transmits forces by the skin friction and the soil resistance under the toe of the pile. It is absolutely obvious. The question is: what is the participation of skin friction and toe resistance in distribution load? Can we interpret these two values independently? To find the answer to these questions, a series of laboratory experiments have been conducted. The research have included static load tests of model concrete pile with a diameter of $7 \mathrm{~cm}$, and length of 20 $\mathrm{cm}$ with appropriate measurement instrumentation to record the resistance under the toe of the pile. Pile was embedded in non-cohesive, homogeneous soil. 


\section{Research Model Description}

The study was conducted on laboratory model of pile in reduced scale. The relationship between the diameter and length of the pile is not directly proportional, but the soil behaviour because of ultimate strength is similar to real pile-soil behaviour. The laboratory test stand consisted of steel chamber, which was $48.5 \mathrm{~cm}$ in diameter and 60 $\mathrm{cm}$ in height. The chamber was filled with non-cohesive soil (medium sand). Pile model with a diameter of $7 \mathrm{~cm}$ and height of $30 \mathrm{~cm}$ was made of concrete. The toe and the head of the pile were specially constructed. Force sensors that measured the load distribution during static load test were installed (Fig. 1). The settlement of the head of the pile, within a range of $0-15 \mathrm{~mm}$, was measured by linear potentiometer installed on independent base. The load was applied using elevating cylinder. The results were read out by data logger connected to a computer. The instrumented pile was calibrated in testing machine under vertical compression load.

\section{Test Procedure}

The soil was placed layer by layer in a chamber and dynamically compacted using $15-\mathrm{kg}$ steel plate. Water content in the soil is about $2-3 \%$. During filling, the density of the sand was measured. In this way, the density was determined in 3 places in the chamber. In addition, after filling the chamber, the relative density of the sand was determined. Next the hole in the soil was made using tube and the pile was inserted. The soil in the 1-2 mm slot surrounding the shaft of the pile was compacted. Afterwards, the sensors and elevating cylinder were set. Finally, we obtained a pile embedded in the soil without influence on the soil structure so we cannot compare this pile to displacement pile, rather to the boring pile.

The research enabled static pile load test. During loading, the settlement and forces of the head and at the toe were measured. The constant load lasted until the stabilisation of the settlement of the pile head. The study was conducted until the $15-\mathrm{mm}$ settlement was achieved. After the test, the stress of soil under the pile base had exceeded the ultimate values. More details about it can be found in a book about non-cohesive soil mechanics by Sawicki [8]. To carry out next test, it was necessary to empty the chamber and fill it again because the destroyed structure of the soil could have a significant impact on the results. In the laboratory of the Department of Geotechnical Engineering, 8 static pile load tests were conducted. Instrumented pile prepared for

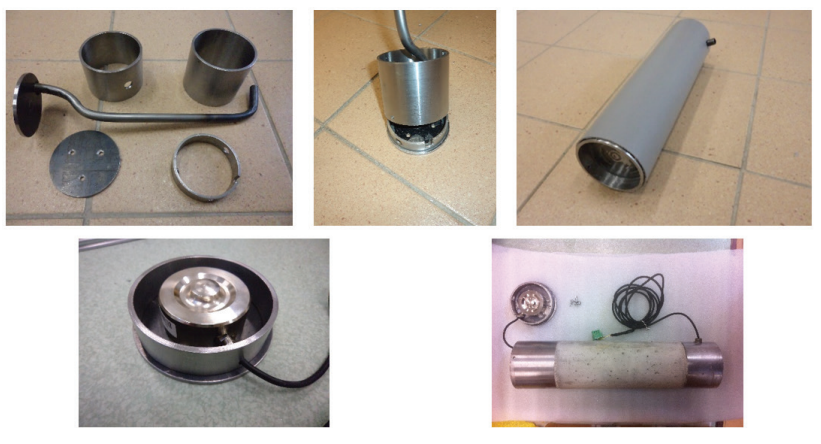

Figure 1: Components of instrumentation pile model.

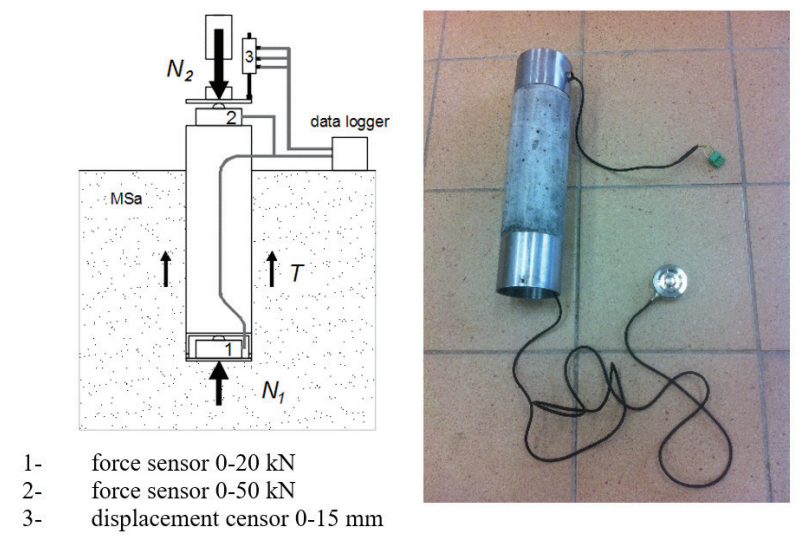

Figure 2: Simplified scheme of the laboratory instrumented pile.

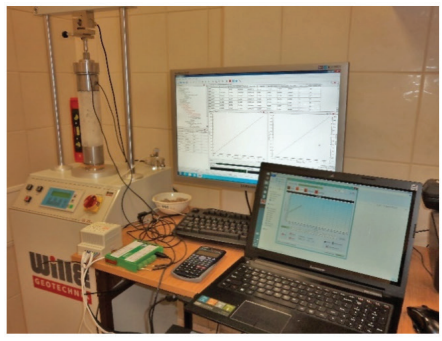

(a)

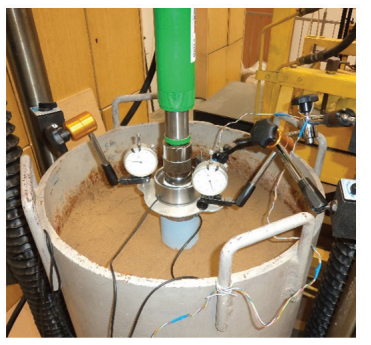

(b)
Figure 3: (a) Calibration of the model instrumented pile. (b) Pile prepared to static load test.

testing is presented in Figures 2 and 3. In the appropriate mathematical description term appears $\mathrm{H} / \mathrm{D}$, which is a scale parameter. The laboratory tests were made for $2.5<\mathrm{H} /$ $\mathrm{D}<9$; however, in the presented article, the description is given only for chosen $\mathrm{H} / \mathrm{D}=2.86$.

\section{Test Results}

The results of this study are the settlement of the pile, the force applied in the head of the pile and the force mobilised under the toe of the pile. The findings are presented in 
Table 1: Comparison of the M-K approximation of piles 1 and 8.

\begin{tabular}{lllllllll}
\hline No & $\begin{array}{l}\text { Diameter } \\
\mathrm{D}(\mathrm{m})\end{array}$ & $\begin{array}{l}\text { Depth } \\
\mathrm{H}(\mathrm{m})\end{array}$ & \multicolumn{2}{c}{ M-K approximation parameters } & & & & \\
& & & $\boldsymbol{C}_{2}(\mathrm{~mm} / \mathrm{kN})$ & $\boldsymbol{N}_{g r, 2}(\mathrm{kN})$ & $\boldsymbol{\kappa}_{2}(-)$ & $\boldsymbol{C}_{1}(\mathrm{~mm} / \mathrm{kN})$ & $\boldsymbol{N}_{g r, 1}(\mathrm{kN})$ & $\boldsymbol{\kappa}_{1}(-)$ \\
\hline 1 & 0.07 & 0.20 & 0.4317 & 6.66 & 0.332 & 0.5362 & 6.28 & 0.288 \\
8 & 0.07 & 0.25 & 0.2079 & 14.69 & 0.348 & 0.28335 & 14.33 & 0.238 \\
\hline
\end{tabular}

Figure 4. Each load step gives two pair of points $\left(N_{2}, s\right)$ and $\left(N_{1}, s\right)$. The completed findings were presented as $s=f\left(N_{2}\right)$ and $s=f\left(N_{1}\right)$. In the next step, the measured data were approximated following the M-K curve (1) [9].

$$
s_{i, \text { calc }}=C \frac{N_{g r}}{\kappa}\left[\left(1-\frac{N_{i, \text { meas }}}{N_{g r}}\right)^{-\kappa}-1\right]
$$

where

$C$ is the settlement curve parameter $(\mathrm{mm} / \mathrm{kN})$,

$N_{g r}$ is the bearing capacity of the pile, when the uncontrolled settlements are observed $(\mathrm{kN})$,

$\kappa$ is the dimensionless parameter of settlement curve (-) $N_{i, \text { meas }}$ is the applied load at $i$ stage $(\mathrm{kN})$,

$s_{i . m e a s}$ is the measured settlement of the head of the pile at $i$ stage of load (mm)

The approximation consisted of numerical searching for $\kappa$ parameter when equation (2) was complied. More information about the procedure of approximation has been described in [4].

$$
\kappa=\text { opt } \Leftrightarrow \sum_{i=1}^{n-1} \Delta^{2}=\min
$$

where $\Delta=\left(s_{i, \text { meas }}-s_{i, \text { calc }}\right)$

For a set of $\left\{N_{2, i}, s_{i}\right\}$ we obtained 3 parameters, $C_{2}, N_{g r, 2}$ and $\kappa_{2}$, and for a collection of $\left\{N_{1, i}, S_{i}\right\}$ we obtained 3 parameters, $C_{1}, N_{g r, 1}$ and $\kappa_{1}$. Comparison of these parameters is presented in Table 1. During the $\mathrm{M}-\mathrm{K}$ approximation, we received the relationship between $k$ parameters and the other parameters of the M-K curve $C$ and $N_{g r}$. The relationships are presented in Figures 5 and 6.

In the further analysis, we concluded the relationship between parameters $C_{2}, N_{g r, 2}$ and $\kappa_{2}$; parameters $C_{1}, N_{g r, 1}$ and $\kappa_{1}$, and geometry of the pile $H, D$, in the following form (3-5).

$$
C_{1}=f\left(N g r_{2}, C_{2}, \kappa_{2}, H, D\right)
$$
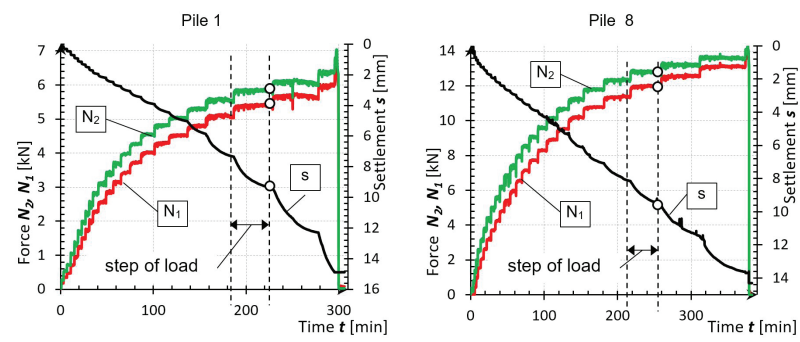

Figure 4: The results of static load tests of two model piles.
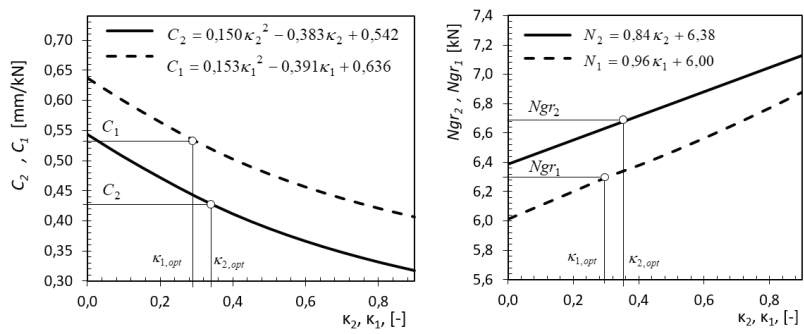

Figure 5: Relationship obtained during the $\mathrm{M}-\mathrm{K}$ approximation for pile 1.
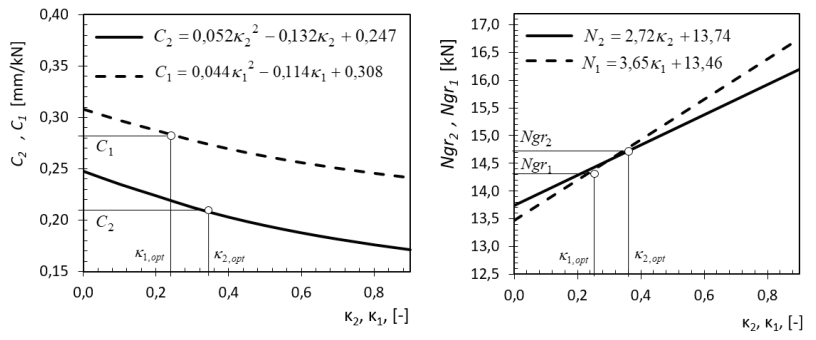

Figure 6: Relationship obtained during the $M-K$ approximation for pile 8.

$$
\begin{gathered}
N g r_{1}=f\left(N g r_{2}, C_{2}, \kappa_{2}, H, D\right) \\
\kappa_{1}=f\left(N g r_{2}, C_{2}, \kappa_{2}, H, D\right)
\end{gathered}
$$

Formulas (3-5) allow us to calculate the parameters of resistance under the toe curve based on the parameters obtained from static load test.

Good approximation on $C_{1}$ parameter was obtained from formula (6) as follows: 


$$
C_{1}=C_{2}\left[1+A\left(\frac{H}{D}\right)^{n_{1}} \cdot\left(\frac{D}{\pi C_{2} N g r_{2}}\right)^{n_{2}} \cdot \kappa_{2}\right]
$$

To determine the components of formula 6, we presented it as equation (7).

$$
\ln \left(\frac{C_{1}}{C_{2}}-1\right)-\ln \left(\kappa_{2}\right)=\ln A+n_{1} \ln \left(\frac{H}{D}\right)+n_{2} \ln \left(\frac{D}{\pi C_{2} N g r_{2}}\right)
$$

Constants $A, n_{1}$ and $n_{2}$ were calculated using least square method, including the new variable:

$Y=\ln \left(\frac{C_{1}}{C_{2}}-1\right)-\ln \left(\kappa_{2}\right), X_{1}=\ln \left(\frac{H}{D}\right), X_{2}=\ln \left(\frac{D}{\pi C_{2} N g r_{2}}\right)$

we have equation (8).

$$
\left\{\begin{array}{l}
\sum_{i=1}^{n} Y=n \ln A+n_{1} \sum_{i=1}^{n} X_{1}+n_{2} \sum_{i=1}^{n} X_{2} \\
\sum_{i=1}^{n} Y X_{1}=n \ln A \sum_{i=1}^{n} X_{1}+n_{1} \sum_{i=1}^{n} X_{1}^{2}+n_{2} \sum_{i=1}^{n} X_{1} X_{2} \\
\sum_{i=1}^{n} Y X_{2}=n \ln A+n_{1} \sum_{i=1}^{n} X_{1} X_{2}+n_{2} \sum_{i=1}^{n} X_{2}^{2}
\end{array}\right.
$$

The set of equation (8) was solved based on data: $C_{2}$, $N_{g r, 2}, \kappa_{2}, C_{1}, N_{g r, 1}, \kappa_{1}, H, D$ from 8 laboratory test. We obtained the following relationship (9):

$$
C_{1}=C_{2}\left[1+0,983\left(\frac{H}{D}\right)^{0,303} \cdot\left(\frac{D}{\pi C_{2} N g r_{2}}\right)^{-0,247} \cdot \kappa_{2}\right]
$$

For bearing capacity of the pile, we received the following formula (10):

$$
N g r_{1}=N_{g r, 2}\left[1-\left(1-\frac{C_{2}}{C_{1}}\right)^{6,04 \kappa_{2}^{0,55}\left(\frac{\mathrm{H}}{D}\right)^{-0,11}}\right]
$$

The parameter $\kappa_{1}$ for presented laboratory tests was described using formula (11).

$$
\kappa_{1}=0,828 \kappa_{2}
$$

\section{Practical Application of This Approach}

Static load test of pile in field tests usually consist of 8 steps of load from force $0 \mathrm{kN}$ to force equals $150 \%$ of designed bearing capacity of the pile. The settlement that is stabilised in each step of test and the applied load are recorded. At the end, we have the relationship between settlement and applied load, which is called as a settlement curve. Following the $\mathrm{M}-\mathrm{K}$ method, we receive 3 parameters: $C_{2}, N_{g r, 2}$ and $\kappa_{2}$. Those parameters are characteristic of the pile, especially its behaviour in specific soil. On the basis of the laboratory test, the equations allow us to calculate $C_{1}, N_{g r, 1}$ and $\kappa_{1}$. In this way, we can define the toe resistance mobilisation following the settlement.

On the basis of the parameters $C_{1}, N_{g r, 1}$ and $\kappa_{1}$ calculated from equations (9), (11) and (12) and parameters received from approximation static load test data $C_{2}$, $N_{g r, 2}$ and $\kappa_{2}$, it is possible to define the resistance on the shaft using the following equation (13).

$$
\begin{aligned}
T(s)=N_{g r, 2}- & N_{g r, 1}+N_{g r, 1}\left[1-\left(1+\frac{\kappa_{1} \cdot s}{C_{1} \cdot N_{g r, 1}}\right)^{-\frac{1}{\kappa_{1}}}\right]- \\
& -N_{g r, 2}\left[1-\left(1+\frac{\kappa_{2} \cdot s}{C_{2} \cdot N_{g r, 2}}\right)^{-\frac{1}{\kappa_{2}}}\right]
\end{aligned}
$$

Interpreting Figures 7 and 8, we can notice the extremum point of skin resistance and settlement. According to EC7, ultimate settlement equals $10 \%$ of diameter of the pile. In laboratory case, it equals $7 \mathrm{~mm}$. During the laboratory tests, the maximum of skin resistance was mobilised in barely $3 \mathrm{~mm}$ of settlement. It should be stressed that the bearing capacities are not the ultimate values. The laboratory test verified the relations. The knowledge of skin and toe resistance mobilisation can be used for the improvement at design procedure of pile capacity.

\section{Conclusions}

The presented laboratory test verified the possibility of drawing the relationship between the $\mathrm{M}-\mathrm{K}$ parameters from static load test and skin resistance mobilisation following the settlement. 
Table 2: Comparison of the $M-K$ approximation of piles 1 and 8 in experiments.

\begin{tabular}{lllllllll}
\hline No. & Diameter D $(\mathrm{m})$ & Length $\mathrm{H}(\mathrm{m})$ & \multicolumn{2}{l}{ Approximation $\mathrm{M}-\mathrm{K}$} & & \multicolumn{2}{c}{ Calculation } \\
& & & $\boldsymbol{C}_{2}(\mathrm{~mm} / \mathrm{kN})$ & $\boldsymbol{N}_{g r, 2}(\mathrm{kN})$ & $\boldsymbol{K}_{2}(-)$ & $\boldsymbol{C}_{1}(\mathrm{~mm} / \mathrm{kN})$ & $\boldsymbol{N}_{g r, 1}(\mathrm{kN})$ & $\boldsymbol{K}_{1}(-)$ \\
\hline 1 & 0.07 & 0.20 & 0.4317 & 6.66 & 0.332 & 0.54848 & 6.59 & 0.275 \\
8 & 0.07 & 0.25 & 0.2079 & 14.69 & 0.348 & 0.27192 & 14.48 & 0.288 \\
\hline
\end{tabular}

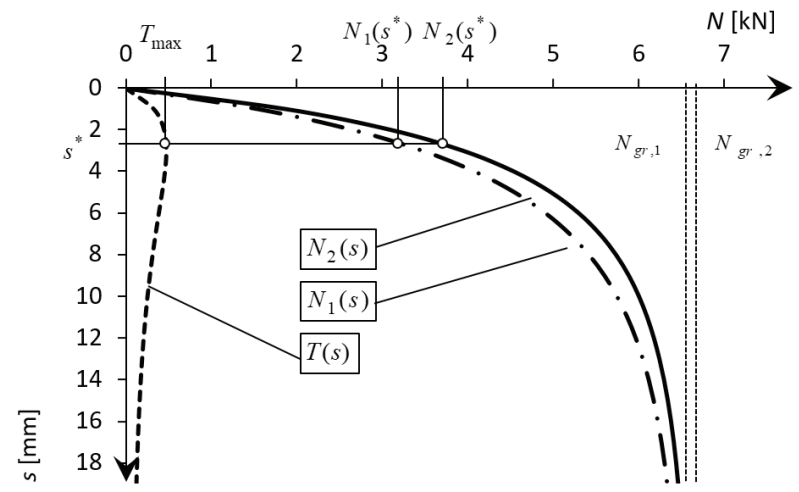

Figure 7: Calculated skin and toe resistance mobilisation following the settlement - pile 1 .

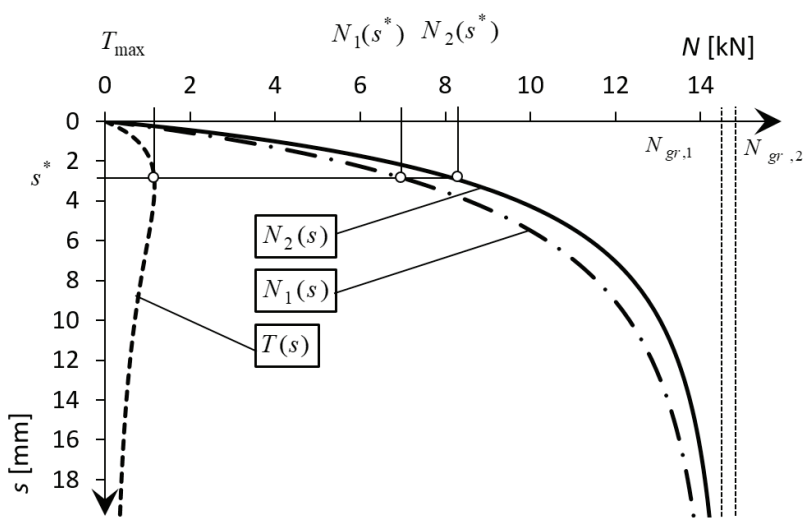

Figure 8: Calculated skin and toe resistance mobilisation following the settlement - pile 8

The figure of skin resistance mobilization indicated the maximum resistance reached at defined settlement. Further increase in settlement resulted in decrease of the skin resistance. It is the aim of further analysis.

In practice, the presented method allows to not only determine the ultimate resistances but also extract the proper value of skin and toe resistance corresponding to the settlement. It may be more rational way in pile capacity designing.

\section{References}

[1] Fellenius, B.H. (2016). Basics of Foundation Design. Electronic edition. Sidney, British Columbia, Canada.

[2] Gwizdała K. (2010). Fundamenty palowe. Wydawnictwo Naukowe PWN, Warszawa.

[3] Gwizdała K., Krasiński A. (2013). Bearing capacity of displacement piles in layered soils with highly diverse strength parameters. [W]: Proceedings of the 18th International Conference on Soil Mechanics and Geotechnical Engineering Ed. by Francois Schlosser Pierre Delage, Jacques Desrues, Roger Frank, Alain Puech. Paris.

[4] Meyer Z. (2014). Static Load Tests, Short Series Interpretation. Studia Geotechnica et Mechanica XXXVI, p:45-49.

[5] Meyer Z., Kowalów M. (2010). Model krzywej aproksymującej wyniki testów statycznych pali. Inżynieria Morska i Geotechnika 3/2010.

[6] Meyer Z., Żarkiewicz K. (2015). Analiza mobilizacji oporu pobocznicy i podstawy pala na podstawie interpretacji badań modelowych. Inżynieria Morska i Geotechnika 3/2015, p:350-354.

[7] Salgado R, Prezzi M., Seo H. (2007). Advanced Modeling Tools for the Analysis of Axially Loaded Piles. Keynote paper and lecture, The Japanese Geotechnical Society, Proc. of the International Workshop on Recent Advances in Deep Foundations, Kumamoto, Japan, February 2007, p.49-67.

[8] Sawicki A. (2012). Zarys mechaniki gruntów sypkich. Wydawnictwo IBW PAN, Gdańsk.

[9] Szmechel G. (2014). Określenie nośności granicznej pali na podstawie próbnych obciążeń statycznych wograniczonym zakresie. Ph.D. Dissertation. West Pomeranian University of Technology in Szczecin. 